\title{
Respiratory symptoms and lung function in a group of solderers
}

\section{COURTNEY AND J D MERRETT}

From Standard Telephones and Cables (N Ireland) Ltd, Newtownabbey, Co Antrim, N Ireland BT36 6 XA, and Department of Medical Statistics, Queen's University, Belfast, UK

ABSTRACT A total of 1611 women working in a large electronics company were interviewed using a modified version of the Medical Research Council's questionnaire on respiratory symptoms, and their lung function was tested using a Vitalograph dry wedge spirometer. When the prevalence of symptoms was compared using the $\chi^{2}$ test among four occupational groups - namely, solderers, ex-solderers, non-solderers, and office workers - few significant differences were found. The group of ex-solderers tended to have a greater prevalence of symptoms than the other three groups. Forced vital capacity (FVC) and forced expiratory volume in one second $\left(F E V_{1}\right)$ were measured, and when these were compared for smokers, the office workers were found to have a greater mean age adjusted FVC and $\mathrm{FEV}_{1}$ than the three other groups. The pattern was less distinct for non-smokers. When duration of exposure to solder fumes was allowed for, differences in lung function were more suggestive of being related to smoking habit than occupational exposure to solder fumes.

Following work by Fawcett $e t$ al $^{1}$ and later by Burge et $a l^{2}$ which suggested that there may be a hitherto unrecognised respiratory problem among workers exposed to the fumes given off when rosin based solder is used in the electronics industry, a study was set up to ascertain if the prevalence of respiratory symptoms in a group of solderers differed appreciably from that in other groups of workers with little or no exposure to solder fumes. In addition, the lung function of the soldering group was compared with the other occupational groups to see if pronounced differences existed between the groups.

\section{Study population}

The study was carried out at four sites located in different parts of the British Isles. Sites 1 and 4 were in Essex, site 2 in Lancashire and site 3 in Northern Ireland.

The work carried out at all the locations was broadly similar, the main consistent feature being that a high proportion of the work entailed soldering. At all the sites studied, the working population was predominantly female, soldering

Received 2 April 1981

Accepted 25 July 1983 jobs being almost exclusively confined to women. All women on each site, irrespective of job function, were therefore enrolled as the study population. The object was to make comparisons between the occupational groups defined below.

A total of 1611 women (86.1\% of those eligible) were studied, all but 14 being Caucasians. Of the total, 202 were ex-smokers. Analyses were carried out on this group in exactly the same way. as for smokers and non-smokers, but the results are not reported here because the numbers in the various subgroups became very small. Nevertheless, no different trends were found in this ex-smoking group. Ten women (six smokers and four non-smokers) admitted on questionnaire to being disabled from walking by reasons other than chest or heart disease. They were excluded from the analysis of respiratory symptoms and lung function.

Four occupational groups were constructed, namely:

Solderer-A woman engaged in a job that included any soldering operation irrespective of the method of soldering.

Ex-solderer-A woman who had soldered in the past but did so no longer although she worked on a shop floor where soldering took place.

Non-solderer-A woman whose job was on a 
shop floor where soldering took place but who had never soldered.

Office-A woman who had always worked in an area where no soldering took place.

Table 1 shows the distribution of the 1399 women fully reported on by smoking habit, occupational group, and age.

Those eligible for inclusion but not seen were either unwilling to take part in the survey or were off site at the time of the study because of illness, holidays, or secondment to other duties on another site. The included and omitted groups, however, were compared with regard to age, occupation, and certified absence. No evidence was found to suggest that the group not seen differed in any important way from the group seen.

\section{Materials and methods}

The prevalence of respiratory symptoms was recorded using a modified version of the Medical Research Council (MRC) Questionnaire on respiratory symptoms. ${ }^{3}$ It was modified by adding questions relating to lachrymation and rhinorrhoea. The questionnaire was administered by the nurse working on each site. At the end of the interview a Vitalograph dry wedge spirometer was used to measure forced vital capacity (FVC) and forced expiratory volume in one second $\left(\mathrm{FEV}_{1}\right)$, the best of three acceptable dynamic tests being recorded. The volumes were recorded in litres measured at body temperature and pressure saturated with water vapour (BTPS).

\section{Statistical analysis}

The prevalence of each respiratory symptom was compared among the four occupational groups. The

Table 1 Distribution of study population by site occupational group, and current smoking habits

\section{๘}

\begin{tabular}{|c|c|c|c|c|c|}
\hline \multirow[b]{2}{*}{$\begin{array}{c}\text { Site } 1 \\
\text { Site } 2 \\
\text { Site } 3 \\
\text { Site } 4 \\
\text { Total }\end{array}$} & \multicolumn{2}{|c|}{ (a) Smokers } & \multirow[b]{2}{*}{$\begin{array}{r}23 \\
51 \\
148 \\
22 \\
244\end{array}$} & \multirow[b]{2}{*}{$\begin{array}{r}5 \\
7 \\
44 \\
17 \\
73\end{array}$} & \multirow[b]{2}{*}{$\begin{array}{l}136 \\
200 \\
322 \\
127 \\
785\end{array}$} \\
\hline & $\begin{array}{r}80 \\
96 \\
81 \\
63 \\
320\end{array}$ & $\begin{array}{r}28 \\
46 \\
49 \\
25 \\
148\end{array}$ & & & \\
\hline $\begin{array}{c}\text { Site } 1 \\
\text { Site } 2 \\
\text { Site } 3 \\
\text { Site } 4 \\
\text { Total }\end{array}$ & $\begin{array}{r}N O 1 \\
60 \\
40 \\
72 \\
45 \\
217\end{array}$ & $\begin{array}{c}\text { noker } \\
11 \\
33 \\
40 \\
14 \\
98\end{array}$ & $\begin{array}{r}19 \\
30 \\
136 \\
16 \\
201\end{array}$ & $\begin{array}{r}14 \\
8 \\
58 \\
18 \\
98\end{array}$ & $\begin{array}{r}104 \\
111 \\
306 \\
93 \\
614\end{array}$ \\
\hline
\end{tabular}

mean age of the occupational/smoking subgroups varies from 35.3 years for solderers who smoked to 40.0 for office workers who smoked. Among nonsmokers the variation is from $\mathbf{3 8 . 4}$ for ex-solderers to 40.4 for non-solderers. The maximum difference in mean age between occupational groups is thus small ( 4.8 years). With this in mind and since age has not been clearly shown to be an important factor in the prevalence of respiratory symptoms in women ${ }^{4}$ no allowance was made for the differences in mean age between the occupational groups. Current smoking habit will have an influence on the prevalence of respiratory symptoms and so separate analyses were carried out for ex-smokers, smokers, and non-smokers, the latter two groups being reported here. The significance of differences in prevalences was assessed by the $\chi^{2}$ test, or where numbers were small by Fisher's exact probability test.

In the analysis of lung function smokers and nonsmokers were considered separately by constructing eight occupational and smoking subgroups. Regression equations were constructed to predict FVC and $\mathrm{FEV}_{1}$ from age and height for the eight subgroups. Several attempts were made to derive useful prediction equations involving various combinations of age, height, age $\times$ height, and height ${ }^{2}$ but when these combinations were used the increase in the multiple regression coefficient (R) was small. For FVC, $R$ was increased by less than 0.01 in $75 \%$ of the subgroups and by less than $0 \cdot 10$ in the remainder. The picture was similar for $\mathrm{FEV}_{1}$. The use of these combinations of predictors therefore, did not result in any great increase in the accuracy of prediction.

The main analysis of lung function was therefore carried out by constructing regression equations to predict FVC and FEV, from age and height, and age only using the same eight subgroups. When age and height were used the lines differed in slope, indicating that to some extent these equations should be treated with caution. There were no significant differences between the subgroups in either mean height or height distribution. The results using prediction equations for lung function involving both age alone and age and height are reported. The mean age and age/height adjusted FVC and $F E V_{1}$ was then compared between occupational groups using analysis of covariance. ${ }^{5}$

Further analysis was carried out to consider the effect of duration of exposure to solder fumes on lung function. This was carried out for both the solderers and ex-solderers groups. Two levels of exposure were considered, less than six years or six years and more. Burge $e t$ al found a median time of six years before symptoms due to solder fumes became recognisable. ${ }^{\circ}$ As before, regression equa- 
tions were constructed to relate age to FVC and $\mathrm{FEV}_{1}$ and comparisons of the mean age adjusted FVC and $\mathrm{FEV}_{1}$ made between exposure groups.

\section{Results}

Tables 2 and 3 show the prevalence of respiratory symptoms by occupational group for smokers and non-smokers.

A statistically significant difference in the prevalence of symptoms between occupational groups was found in only one instance. Significantly fewer smoking solderers admitted to one week or more withdrawal from their activities in the previous three years due to chest illness than did those who smoked in the other three groups. The higher prevalence of breathlessness plus wheezing in this group and the lower prevalence in office workers do not reach significance at the $5 \%$ level. One trend, however, is fairly consistently found throughout all the symptoms in both smoking categories - that is, that the ex-soldering group tends to have a higher prevalence of symptoms than the three other occupational groups.

The number of symptoms reported by each person was considered to see if this could be accounted for by a few women reporting most of the symptoms. The distribution of number of symptoms per individual did not differ between the occupational groups for either smokers $\left(\chi^{2}=20 \cdot 5, \mathrm{df}=15\right.$,
$0 \cdot 20>\mathrm{p}>0 \cdot 10)$ or non-smokers $\left(\chi^{2}=16 \cdot 9, \mathrm{df}=12\right.$, $0 \cdot 20>\mathrm{p}>0 \cdot 10)$.

\section{IRRITATIVE SYMPTOMS BY OCCUPATIONAL GROUP}

Running eyes and nose and hoarseness are symptoms suggestive of irritation by solder fumes. No significant differences were shown in the prevalence of these symptoms between the occupational groups in either smokers or non-smokers. Among smokers, solderers tended to have the greatest prevalence of running eyes and nose.

\section{LUNG FUNCTION}

Various attempts were made to allow for the effect of age and height on lung function. Regression equations of the form $Y=A+b_{1} X_{1}+b_{2} X_{2}$ where $Y$ is the lung volume (FVC or $\left.F E V_{1}\right), X_{1}$ is age in years, $X_{2}$ is height in metres, and $a, b_{1}, b_{2}$ are constants, were constructed and the results are shown in tables 4 and 5. The results obtained (in brackets) when regression equations were constructed using age only as a predictor are also known. The values of the correlation coefficients obtained from the equations varied from 0.52 to 0.74 ( 0.43 to 0.66 for age only) indicating the percentage variability of FVC and $\mathrm{FEV}_{1}$ associated with differences in age and height ranged from $27 \%$ to $55 \%$ (18\% to $44 \%$ associated with age alone).

When FVC and $\mathrm{FEV}_{1}$ were adjusted to a common

Table 2 Prevalence (\%) of respiratory symptoms by occupation

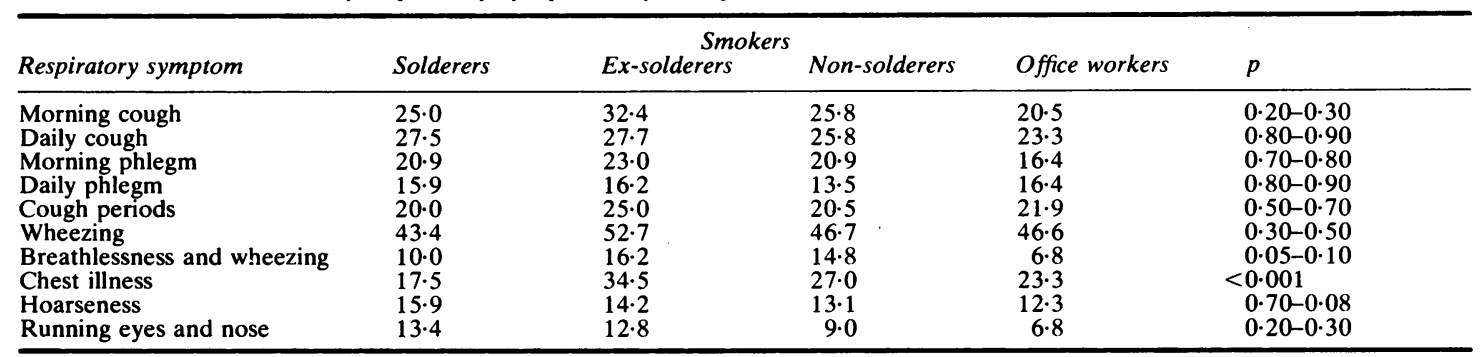

Table 3 Prevalence (\%) of respiratory symptoms by occupation

\begin{tabular}{|c|c|c|c|c|c|}
\hline Respiratory symptoms & Solderers & $\begin{array}{r}\text { Non-s } \\
\text { Ex-solderers }\end{array}$ & Non-solderers & Office workers & $\boldsymbol{p}$ \\
\hline $\begin{array}{l}\text { Morning cough } \\
\text { Daily cough } \\
\text { Morning phlegm } \\
\text { Daily phlegm } \\
\text { Cough periods } \\
\text { Wheezing } \\
\text { Breathlessness and wheezing } \\
\text { Chest illness } \\
\text { Hoarseness } \\
\text { Running eyes and nose }\end{array}$ & $\begin{array}{r}7 \cdot 4 \\
11 \cdot 1 \\
6 \cdot 9 \\
4 \cdot 6 \\
14 \cdot 3 \\
16 \cdot 1 \\
5 \cdot 5 \\
18 \cdot 9 \\
10 \cdot 6 \\
9 \cdot 2\end{array}$ & $\begin{array}{r}12 \cdot 2 \\
15 \cdot 3 \\
13 \cdot 3 \\
8 \cdot 2 \\
16 \cdot 3 \\
22 \cdot 4 \\
12 \cdot 2 \\
23 \cdot 5 \\
16 \cdot 3 \\
8 \cdot 2\end{array}$ & $\begin{array}{r}6 \cdot 0 \\
8 \cdot 0 \\
8 \cdot 0 \\
5 \cdot 0 \\
10 \cdot 9 \\
17 \cdot 4 \\
7 \cdot 0 \\
15 \cdot 9 \\
10 \cdot 0 \\
11 \cdot 4\end{array}$ & \begin{tabular}{r|}
$7 \cdot 1$ \\
$6 \cdot 1$ \\
$6 \cdot 1$ \\
$4 \cdot 1$ \\
$13 \cdot 3$ \\
$10 \cdot 2$ \\
$6 \cdot 1$ \\
$14 \cdot 3$ \\
$13 \cdot 3$ \\
$8 \cdot 2$
\end{tabular} & $\begin{array}{l}0.20-0.30 \\
0.10-0.20 \\
0.20-0.30 \\
0.50-0.70 \\
0.50-0.70 \\
0.10-0.20 \\
0.10-0.20 \\
0.30-0.50 \\
0.30-0.50 \\
0.70-0.80\end{array}$ \\
\hline
\end{tabular}


Table 4 Regression equations to predict FVC from age and height and from age alone. (Values in parentheses for age only)

\begin{tabular}{|c|c|c|c|c|c|}
\hline & $a$ & $b_{1}$ & $b_{2}$ & $R(r)$ & $S^{2}$ \\
\hline \multicolumn{6}{|c|}{ (a) $S$} \\
\hline Solderers & $-1 \cdot 70$ & -0.03 & 3.79 & $\begin{array}{c}0.63 \\
(-0.51)\end{array}$ & $0 \cdot 25$ \\
\hline Ex-solderers & $\begin{array}{l}(4 \cdot 56) \\
-1 \cdot 15\end{array}$ & $\begin{array}{c}(-0.03) \\
-0.02\end{array}$ & $\overline{3} \cdot 42$ & $\begin{array}{c}(-0.51) \\
0.63\end{array}$ & $\begin{array}{c}(0.31) \\
0.22\end{array}$ \\
\hline LA-30incticts & $(4 \cdot 46)$ & $(-0.03)$ & - & $(0.05)$ & $(0.03)$ \\
\hline Non-solderers & -2.58 & -0.03 & $4 \cdot 50$ & 0.66 & 0.27 \\
\hline Office workers & $\begin{array}{r}(4 \cdot 63) \\
-2.81)\end{array}$ & $\begin{array}{r}(0.03) \\
-0.02\end{array}$ & $\overline{4} .50$ & $\left(\begin{array}{r}-0.55) \\
0.63\end{array}\right.$ & $\begin{array}{c}(0.33) \\
0.23\end{array}$ \\
\hline Uince workets & $(4 \cdot 59)$ & $\begin{array}{l}(-0.02) \\
\text { (b) Non-smokers }\end{array}$ & 4.50 & $(-0.44)$ & $(0 \cdot 30)$ \\
\hline Solderers & $-3 \cdot 88$ & -0.02 & $5 \cdot 17$ & $\begin{array}{c}0.66 \\
(-0.48)\end{array}$ & 0.27 \\
\hline Ex-solderers & $\begin{array}{l}(4 \cdot 30) \\
-4 \cdot 10\end{array}$ & $\begin{array}{l}(-0.03) \\
-0.02\end{array}$ & $\overline{5} \cdot 29$ & $\begin{array}{c}(-0.46) \\
0.68\end{array}$ & 0.22 \\
\hline & $(4 \cdot 45)$ & $(-0.03)$ & & $(-0.49)$ & $(0.31)$ \\
\hline Non-solderers & -0.07 & -0.02 & $3 \cdot 13$ & 0.52 & $0 \cdot 32$ \\
\hline & $(4 \cdot 31)$ & $(-0.03)$ & & $(-0.43)$ & $(0.35)$ \\
\hline Office workers & -3.69 & -0.03 & $5 \cdot 11$ & $\begin{array}{r}0.69 \\
(-0.56)\end{array}$ & 0.25 \\
\hline
\end{tabular}

$r=$ Product moment correlation coefficient.

$\mathrm{S}^{2}=$ Variance from regression.

$\mathbf{R}=$ Multiple correlation coefficient.

Table 5 Regression lines to predict FEV, from age and height and from age alone. (Values in parentheses for age only)

\begin{tabular}{|c|c|c|c|c|c|}
\hline & $a$ & $b_{1}$ & $b_{2}$ & $R(r)$ & $S^{2}$ \\
\hline Solderers & $\begin{array}{c}-0.58 \\
-(4.09)\end{array}$ & \multirow{11}{*}{$\begin{array}{l}\text { (a) Smokers } \\
-0.03 \\
(-0.04) \\
-0.03 \\
(-0.03) \\
-0.04 \\
(-0.04) \\
-0.03 \\
(-0.03) \\
(b) \text { Non-smokers } \\
-0.03 \\
(-0.03) \\
-0.03 \\
(-0.03) \\
0.03 \\
(-0.03) \\
-0.03 \\
(-0.04)\end{array}$} & $2 \cdot 87$ & 0.70 & 0.21 \\
\hline Ex-solderers & $\begin{array}{r}(4 \cdot 09) \\
-0.81\end{array}$ & & $\overline{2} .98$ & $\begin{array}{c}(-0.64) \\
0.70\end{array}$ & $\begin{array}{c}(0.25) \\
0.21\end{array}$ \\
\hline & $(4 \cdot 07)$ & & & $(-0.64)$ & $(0.24)$ \\
\hline Non-solderers & -0.88 & & $3 \cdot 11$ & 0.67 & 0.26 \\
\hline Office workers & $\begin{array}{c}(4 \cdot 09) \\
-2 \cdot 50 \\
(4.08)\end{array}$ & & $\begin{array}{l}\overline{4} \cdot 00 \\
-\end{array}$ & $\begin{array}{r}(-0.62) \\
0.66 \\
(-0.52)\end{array}$ & $\begin{array}{c}(0.29) \\
0.22 \\
(0.28)\end{array}$ \\
\hline Solderers & & & 3.99 & & \\
\hline Solderers & $(4 \cdot 08)$ & & - & $(-0.58)$ & $(0.26)$ \\
\hline Ex-solderers & -1.83 & & 3.65 & 0.74 & 0.15 \\
\hline Non-solderers & $\begin{array}{c}(4 \cdot 06) \\
0.00\end{array}$ & & $\overline{2} \cdot 42$ & $\begin{array}{c}(-0.65) \\
0.61\end{array}$ & $\begin{array}{c}(0.20) \\
0.22\end{array}$ \\
\hline & $(3.89)$ & & - & $(-0.56)$ & $(0.24)$ \\
\hline Office workers & $\begin{array}{c}-0.89 \\
(4 \cdot 28)\end{array}$ & & $\begin{array}{l}3 \cdot 13 \\
-\end{array}$ & $\begin{array}{c}0.71 \\
(-0.66)\end{array}$ & $\begin{array}{c}0.21 \\
(0.24)\end{array}$ \\
\hline
\end{tabular}

$\mathbf{r}=$ Product moment correlation coefficient.

$\mathrm{S}^{2}=$ Variance from regression.

$\mathbf{R}=$ Multiple correlation coefficient.

age and height several differences were noted among the groups (table 6). Among smokers, office workers had a larger mean FVC and FEV, than the three other groups. When non-smokers were considered the mean age/height adjusted FVC and FEV of non-solderers was smaller than the three other groups. As mentioned earlier, because of theoretical difficulties relating to the slopes of the regression equations, formal significance testing was not carried out on these adjusted lung volumes.

The FVC and FEV, adjusted to a common age are shown in table 6. Smoking office workers had significantly larger FVC and $F E V_{1}$ than the three other groups; non-smoking office workers had significantly larger mean age adjusted FVC and $\mathrm{FEV}_{1}$ than non-smoking non-solderers. This latter group had a smaller mean age adjusted $\mathrm{FEV}_{1}$ than solderers.

It can be seen that the use of age and height as predictors causes the mean lung volume of the four occupational groups to be closer than when age alone is used.

\section{DURATION OF EXPOSURE}

Further analysis was carried out to consider the possible effects of differing periods of exposure to solder fumes. The solderers and ex-solderers were considered for two periods of exposure, less than six years and six years or more. The short exposure group had a mean age of 33.1 years for smoking solderers and 35.7 years for non-smoking solderers ( $37 \cdot 8$ years and 38.2 years for ex-solderers) while in 
Table 6 Comparison of mean FVC and FEV adjusted to a common age and height (age only) by occupation and current smoking habit. (Values in parentheses show lung volumes adjusted to a common age only)

\begin{tabular}{lcc}
\hline & $F V C(l)$ & $F E V_{1}(l)$ \\
\hline \multirow{3}{*}{ Solderers } & $($ a) Smokers & \\
Ex-solderers & 3.42 & 2.77 \\
Non-solderers & $(3.41)$ & $(2.76)$ \\
& 3.41 & 2.76 \\
Office workers & $(3.43)$ & $(2.78)$ \\
& 3.42 & 2.72 \\
& $(3.39)$ & $(2.70)$ \\
Solderers & 3.57 & 2.90 \\
& $(3.67)$ & $(2.97)$ \\
Ex-solderers & $(b)$ Non-smokers & 2.84 \\
& 3.43 & $(2.85)$ \\
Non-solderers & $(3.44)$ & 2.86 \\
& 3.47 & $(2.83)$ \\
Office workers & $(3.44)$ & 2.74 \\
& 3.35 & $(2.72)$ \\
& $(3.32)$ & 2.85 \\
& 3.45 & $(2.89)$ \\
\hline
\end{tabular}

Table 7 Mean FVC and FEV, adjusted to a common age by duration of exposure

\begin{tabular}{llll}
\hline & Exposure (y) & FVC (l) & FEV $(l)$ \\
\hline \multirow{4}{*}{ Solderers } & (a) Smokers & & \\
& $<6$ & 3.53 & 2.90 \\
Ex-solderers & $\geqslant 6$ & 3.33 & 2.69 \\
& $<6$ & 3.39 & 2.72 \\
& $\geqslant 6$ & 3.37 & 2.72 \\
Solderers & (b) Non-smokers & \\
& $<6$ & 3.44 & 2.86 \\
& $\geqslant 6$ & 3.45 & 2.86 \\
\hline
\end{tabular}

Table 8 Values of mean age, height, FVC, FEV for solderers who have smoked for 30 years or more by duration or exposure to soldering

\begin{tabular}{llllll}
\hline $\begin{array}{l}\text { Duration of } \\
\text { exposure }(y)\end{array}$ & No & $\begin{array}{l}\text { Age } \\
(y)\end{array}$ & $\begin{array}{l}\text { Height } \\
(m)\end{array}$ & FVC $(l)$ & FEV $(l)$ \\
\hline$<6$ & 28 & 51.4 & 1.58 & 2.88 & 2.21 \\
$\geqslant 6$ & 25 & 51.8 & 1.60 & 2.91 & 2.12 \\
\hline
\end{tabular}

the longer exposure group the mean ages were 41.9 years for smoking solderers and 44.1 years for nonsmoking solderers $(45.9$ years and 39.7 years for ex-solderers). There were no significant differences in the mean heights of the groups.

In the non-smoking ex-solderers groups there was no difference between the mean lung volumes of the two exposure groups. In the three other subgroups differences were noted in the mean lung volumes of the two exposure groups.

When the mean lung volumes were adjusted to a common age (table 7) it could be seen that there were no significant differences in FVC or FEV, for non-smoking solderers and smoking ex-solderers. The mean age adjusted FVC and FEV ${ }_{1}$ of the smoking solderers group, however, still shows significantly lower values in the group with the long exposure than in those exposed for under six years.

In order to minimise the confounding effect that smoking might have on lung function, long term and short term solderers, all of whom had smoked for more than 30 years, were compared (table 8 ). The mean age, height, FVC, and FEV 1 of the two groups were very similar, no statistically significant differences being noted. This suggests that the differences in lung function between the two exposure groups is more likely to be due to smoking habits than to exposure to solder fumes.

\section{Discussion}

\section{SYMPTOMS}

In considering the respiratory symptoms few significant differences worthy of note became apparent between the occupational groups, either among smokers or non-smokers. Furthermore, when trends were considered between the groups, generally speaking, the office or control group did not emerge as having an appreciably lower prevalence of symptoms than the other groups. Thus when both trends in prevalence and their statistical significance were considered, there was no evidence to suggest that the exposed group had more respiratory symptoms than the non-exposed groups. One trend, however, was consistent-that is, that for almost all the respiratory symptoms the group of ex-solderers had the highest prevalence. This observation suggests the possibility that the ex-solderers might have been transferred from a soldering job because of the respiratory effects of the fumes.

The medical and personnel records of all the exsolderers on site 3 were examined to try to determine the reasons for transfer from soldering jobs. The results for site 3 alone were so similar to those reported for all sites combined that it was thought reasonable to assume that the ex-soldering group at this site would reflect the experience of all exsolderers. There were 109 women in the group of ex-solderers on site 3. Personnel records were of little help but from the medical records it was found that only five of the ex-solderers had been moved from soldering for medical reasons and in all cases the transfer was due to medical conditions with other known causes. These findings do not support the view, therefore, that the ex-solderers group is made up of a large number of employees who have been transferred because of medical problems related to soldering.

In addition, the possibility that a few of the women complained of a large number of the respiratory symptoms was not confirmed since the distribution of the number of symptoms per 
individual did not show any significant differences between groups.

The possibility that solderers developed medical problems and as a result left their employment could not, unfortunately, be investigated because of the difficulties of tracing those who had left the company in the past 15 years.

Several extra questions were added to the MRC questionnaire and their inclusion requires some comment. Certain irritative symptoms (hoarseness and running or watering eyes and nose) have been considered to follow exposure to solder fumes.? When threshold limit values (TLV) were set these were the symptoms that were considered as an index of exposure to solder fumes and the prevalence of irritative symptoms was found to be greatly reduced when the levels of aliphatic aldehydes in the fume fell below $0 \cdot 1 \mathrm{mg} / \mathrm{m}^{3}$. This was therefore taken as the TLV from rosin based solder fumes. ${ }^{8}$ In this study no significant differences were found in the prevalence of irritative symptoms among the four occupational groups.

\section{LUNG FUNCTION}

Reference has been made above to the consideration of the factors having a bearing on lung volumes. Various combinations of age and height were used in attempts to predict lung function but it was found that adjusting to a common age gave the most theoretically acceptable statistical results. The long accepted adjustment, however, is to allow for age and height. By doing this, however, the only real effect was to bring the mean age/height adjusted lung volumes for each of the subgroups closer together, minimising further any differences found between the occupational groups. Other combinations of age and height did not improve the correlation coefficient to any great degree. There is thus no evidence to suggest that consideration of age adjusted lung volumes and their comparison among occupational groups is in any way misleading.

The striking feature of the mean age adjusted ventilatory volumes was the different trends found in the smoking and non-smoking categories. Occupational comparisons among smokers showed that the office group had a significantly larger mean age adjusted FVC and FEV 1 than the other three groups. The main possibilities that may account for these differences are that they may be the effects of the workers' occupation, or of their smoking habits, or a combination of both. The observations that no comparable significant differences were found in the non-smokers is important. While the trend in this category was again for the mean age adjusted FVC and FEV $V_{1}$ to be greater in office workers than in the three other occupational groups, these differences were only significant between office and nonsoldering groups. While these differences are statistically significant, their clinical significance is less clear. The largest differences, of the order of 0.271 for both FVC and FEV ${ }_{1}$, are observed between the office and non-soldering groups and, from a clinical standpoint, these differences are small. If, therefore, it is assumed that the four occupational groups represent gradations of exposure to solder fumes these observations do not indicate an associated gradation in lung function.

It is reasonable to expect that any effect of soldering on lung function will be more apparent in groups who have been exposed to soldering for longer periods. More individuals in these groups will show the effect, and the effect in each individual will be greater. Since Burge et al have shown that the median duration of exposure before the appearance of symptoms referable to soldering is six years, ${ }^{2}$ comparisons were made between those exposed for less than six years and six years and more and the

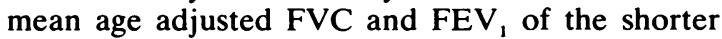
exposure group were found to be'significantly greater than that of the longer exposure group among smokers but not among non-smokers. It was therefore essential to attempt to allow for the effect of the duration of smoking on lung function. By considering solderers who had smoked for more than 30 years some helpful information was obtained indicating that when age and duration of smoking were held constant there were no differences between the mean FVC and FEV of the two groups with different exposure to soldering thus suggesting that the differences in lung function observed in other groups were reflecting smoking habits rather than exposure to solder fumes.

\section{References}

' Fawcett JW, Newman-Taylor AJ, Pepys J. Asthma due to inhaled chemical agents-fumes from "Multicore" soldering flux and colophony resin. Clin Allergy 1976;6:577-85.

${ }^{2}$ Burge PS, Harries MG, O'Brien IM, Pepys J. Respiratory disease in workers exposed to solder flux fumes containing colophony (pine resin). Clin Allergy 1978;8:1-14.

${ }^{3}$ Medical Research Council. Questionnaire on respiratory symptoms 1976. London: MRC, 1976.

+Anderson DO, Ferris BG, Zickmantal R. The Chilliwack respiratory survey $1963,1 \mathrm{~V}$. The effect of tobacco smoking on the prevalence of respiratory disease. Can Med Assoc J 1965;92: 1066-76.

${ }^{5}$ Quenoville MH. Associated measurements. London: Butterworths Scientific Publications 1952.

- Burge PS, Perks W, O'Brien IM, Hawkins R, Green M. Occupational asthma in an electronics factory. Thorax 1979;34:13-8.

' Christie HR. The development of the threshold limit value of rosin smoke in air. Indianopolis: Clarkson College of Technology, 1973. (Thesis.)

${ }^{*}$ HM Factory Inspectorate. Threshold limit values. London: HMFI, 1974:13 (Guidance note.) (EH15/80.) 